\title{
TERT promoter mutations and long-term survival in patients with thyroid cancer
}

\author{
Tae Hyuk Kim 1,*, Young-Eun Kim²,*, Soomin Ahn',*, Ji-Youn Kim, Chang-Seok Ki5, \\ Young Lyun Oh${ }^{3}$, Kyunga Kim6, Jae Won Yun7,8, Woong-Yang Park7,8, Jun-Ho Choe9, \\ Jung-Han Kim9, Jee Soo Kim ${ }^{9}$, Sun Wook Kim¹ and Jae Hoon Chung ${ }^{1}$ \\ 1Division of Endocrinology and Metabolism, Department of Medicine, Thyroid Center, Samsung Medical Center, \\ Sungkyunkwan University School of Medicine, Seoul, Korea \\ ${ }^{2}$ Green Cross Genome, Yongin, Korea \\ ${ }^{3}$ Department of Pathology, Samsung Medical Center, Sungkyunkwan University School of Medicine, Seoul, Korea \\ ${ }^{4}$ Center for Clinical Medicine, Samsung Biomedical Research Institute, Samsung Medical Center, Seoul, Korea \\ ${ }^{5}$ Department of Laboratory Medicine and Genetics, Samsung Medical Center, Sungkyunkwan University \\ School of Medicine, Seoul, Korea \\ ${ }^{6}$ Biostatistics and Clinical Epidemiology Center, Research Institute for Future Medicine, Samsung Medical Center, \\ Sungkyunkwan University School of Medicine, Seoul, Korea \\ ${ }^{7}$ Samsung Genome Institute, Samsung Medical Center, Seoul, Korea \\ ${ }^{8}$ Department of Molecular Cell Biology, Sungkyunkwan University School of Medicine, Suwon, Korea \\ ${ }^{9}$ Division of Breast and Endocrine Surgery, Department of Surgery, Samsung Medical Center, \\ Sungkyunkwan University School of Medicine, Seoul, Korea \\ *(T H Kim, Y-E Kim and S Ahn are co-first authors for this work)
}

Correspondence should be addressed to $\mathrm{J} \mathrm{H}$ Chung Email thyroid@skku.edu

\begin{abstract}
TERT promoter mutations are emerging prognostic biomarkers in multiple cancers and are found in highly aggressive thyroid cancer. Our aim is to investigate the prognostic value of these mutations for the outcome of thyroid cancer-related mortality in a large cohort of thyroid cancer patients. This was a retrospective study of 409 patients (393 with differentiated thyroid cancer) with a median age of 44 years (range 16-81 years) and median follow-up of 13 years (interquartile range 11-16 years). Analyses of associations between mutational status and various clinicopathological variables were performed. TERT promoter mutations were identified in 32 (9.8\%) papillary, 11 (16.7\%) follicular and seven (43.8\%) poorly differentiated/anaplastic thyroid cancer patients. The presence of TERT promoter mutations was associated with factors such as increased age $(P<0.001)$, extrathyroidal invasion $(P=0.01)$, increased stage at diagnosis $(P<0.001)$ and dedifferentiated histological type $(P=0.001)$. A TERT promoter mutation was independently associated with poorer overall survival in patients with differentiated thyroid cancer (10-year survival rate, $66.2 \%$ vs $98.3 \%$ for wild type; adjusted HR, 7.18; $95 \% \mathrm{Cl}$ : $2.77-18.59$ ) and in patients with papillary cancer $(74.2 \%$ vs $99.3 \% ; 14.20 ; 3.03-66.68)$. Concomitant TERT and BRAF mutations worsened the survival rate of patients with papillary cancer (82.6\% vs $99.4 \%$ for exclusively BRAF mutation alone; $5.62 ; 1.85-17.09)$. In conclusion, the presence of TERT promoter mutations is independently associated with increased mortality in patients with differentiated thyroid cancer. The results suggest that inclusion of TERT promoter mutation analysis with conventional clinicopathological evaluation can lead to better prognostication and management for individual patients.
\end{abstract}
Key Words
- thyroid cancer
- TERT promoter
- BRAF
- prognosis
mortality

C 2016 Society for Endocrinology Printed in Great Britain
Published by Bioscientifica Ltd
Endocrine-Related Cancer (2016) 23, 813-823 


\section{Introduction}

Thyroid cancer is the most common endocrine malignancy, and its prevalence is increasing worldwide (Chen et al. 2009). In the USA, the 10-year overall survival rates for papillary thyroid cancer (PTC), follicular thyroid cancer (FTC) and poorly differentiated/anaplastic thyroid cancer (PDTC/ATC) are approximately 93, 85 and $14 \%$, respectively (Hundahl et al. 1998). Given the increased likelihood of long-term survival in patients with differentiated thyroid cancer, it is important to distinguish patients who need aggressive treatment to reduce mortality from those who do not. Several clinicopathological prognostic variables have been used to stratify cancer patients, including increased age, histological type, tumor size, direct local tumor invasion, lymph node metastasis and distant metastasis (DeGroot et al. 1990, Mazzaferri $\&$ Kloos 2001). These conventional risk factors, alone or in combination as a component of staging system (Hay et al. 1993, Edge et al. 2010), imperfectly predict the final outcome of each individual patient.

Recently, molecular marker-based risk stratification of thyroid cancer has been proposed to better estimate the risk (Xing et al. 2013b). The v-Raf murine sarcoma viral oncogene homolog B (BRAF) T1799A mutation has drawn much attention based on its high prevalence, occurring in about $45 \%$ of PTC and $25 \%$ of ATC cases and its association with PTC recurrence (Kim et al. 2012, Xing et al. 2015). However, many clinicians note that the mutation is common, whereas thyroid cancer-related mortality in patients with PTC is low. In a large multicenter study of 1849 patients with PTC, the BRAF T1799A mutation was associated with an increased cancer-related mortality, but it was no longer significant after the adjustment of risk factors, such as lymph node metastasis, extrathyroidal invasion and distant metastasis (Xing et al. 2013a).

In 2013, recurrent point mutations were found in the telomerase reverse transcriptase (TERT) promoter in $71 \%$ of melanoma genomes, and these somatic mutations enhanced promoter activity by two- to four-fold (Horn et al. 2013, Huang et al. 2013), which might immortalize proliferative cancer cells by maintaining telomere length (Vinagre et al. 2014). Starting with the seminal work of Liu and coworkers (2013), the importance of these findings has been reinforced in thyroid cancer by the association of mutations with tumor aggressiveness, early recurrence and even patient mortality (Melo et al. 2014, Xing et al. $2014 a, b$, Song et al. 2015). This potential prognostic marker is very promising, but its relationship to the longterm survival of patients with thyroid cancer requires further study. Currently, none of the mortality risk systems takes molecular testing results into consideration. It is still unclear if patients with TERT promoter-mutated thyroid cancer should be managed differently than those with wild-type tumor. The goal of our study is to investigate the association of TERT promoter mutations with thyroid cancer-specific survival to lead to more informed decisions and better management of thyroid cancer.

\section{Subjects and methods}

\section{Patients and clinicopathological data}

The Institutional Review Board at Samsung Medical Center, Seoul, Korea, approved the study protocol and the use of human thyroid tissue. This study included 409 patients with thyroid cancer. All patients were treated with initial thyroidectomy (398 total or near-total thyroidectomy and 11 less than total thyroidectomy) and therapeutic neck dissection from October 1994 to December 2004. All patients received standard thyrotropin suppression, and 376 of them received radioiodine ablation as guided by standard criteria (Cooper et al. 2006, 2009). Sample characteristics obtained from medical records are presented in Table 1. Thyroid cancer samples were obtained from the tissue archives of the Department of Pathology of the Samsung Medical Center. Only one sample per individual was included. All mutational analyses were performed after surgical and radioiodine treatment of patients, and the test results did not affect the decision-making process of the acting physician. Thyroid cancer-related mortality, based on the date of registration of death where the primary cause of death was thyroid cancer, was obtained from the Korea National Statistical Office and hospital medical records.

\section{DNA isolation from thyroid cancer samples}

Tumor cells with a percentage greater than $75 \%$ were dissected under microscopy from $4 \mu \mathrm{m}$ unstained sections by comparison with hematoxylin- and eosinstained slides according to a standard protocol (Kim et al. 2014). Genomic DNA was extracted using a Qiagen DNA FFPE Tissue Kit (Qiagen) according to the manufacturer's instructions.

\section{Detection of TERT promoter mutations}

Semi-nested polymerase chain reaction (PCR) was carried out to identify TERT promoter mutations 
Table 1 Summary of clinical and genetic characteristics of 409 thyroid cancer patients.

\begin{tabular}{|c|c|}
\hline Characteristic & $\boldsymbol{N}(\%)$ \\
\hline \multicolumn{2}{|l|}{ Sex } \\
\hline Female & $339(82.9)$ \\
\hline Male & $70(17.1)$ \\
\hline \multicolumn{2}{|l|}{ Age (years) } \\
\hline Median & 44 \\
\hline Range & $16-81$ \\
\hline$<45$ & $226(55.3)$ \\
\hline$\geq 45$ & $183(44.7)$ \\
\hline \multicolumn{2}{|c|}{ TERT promoter mutations } \\
\hline WT & $359(87.8)$ \\
\hline $228 \mathrm{C}>\mathrm{T}$ & $46(11.2)$ \\
\hline $250 \mathrm{C}>\mathrm{T}$ & $4(1.0)$ \\
\hline \multicolumn{2}{|l|}{$B R A F$ mutation } \\
\hline WT & $121(29.6)$ \\
\hline $1799 \mathrm{~T}>\mathrm{A}$ & $202(49.4)$ \\
\hline Missing data & $86(21.0)$ \\
\hline \multicolumn{2}{|c|}{ Histological type } \\
\hline PTC & $327(80.0)$ \\
\hline FTC & $66(16.1)$ \\
\hline PDTC/ATC & $16(3.9)$ \\
\hline \multicolumn{2}{|l|}{ Multifocality } \\
\hline Absent & $299(73.1)$ \\
\hline Present & $110(26.9)$ \\
\hline \multicolumn{2}{|c|}{ Lymph node metastasis } \\
\hline Absent & $206(50.4)$ \\
\hline Present & $201(49.1)$ \\
\hline Missing data & $2(0.5)$ \\
\hline \multicolumn{2}{|c|}{ Extrathyroidal invasion } \\
\hline Absent & $111(27.1)$ \\
\hline Present & $248(60.6)$ \\
\hline Missing data & $50(12.2)$ \\
\hline \multicolumn{2}{|c|}{ Distant metastasis } \\
\hline Absent & $384(93.9)$ \\
\hline Present & $25(6.1)$ \\
\hline \multicolumn{2}{|c|}{ Stage at diagnosisa } \\
\hline 1 & $222(54.3)$ \\
\hline II & $26(6.4)$ \\
\hline III & $103(25.2)$ \\
\hline IV & $58(14.2)$ \\
\hline \multicolumn{2}{|l|}{ Tumor size } \\
\hline Median & 2.8 \\
\hline Range & $0.4-13.0$ \\
\hline$<2.0 \mathrm{~cm}$ & $45(11.0)$ \\
\hline $2.0-4.0 \mathrm{~cm}$ & $302(73.8)$ \\
\hline$>4.0 \mathrm{~cm}$ & $62(15.2)$ \\
\hline
\end{tabular}

$B R A F$, v-Raf murine sarcoma viral oncogene homolog B; FTC, follicular thyroid cancer; PDTC/ATC, poorly differentiated/anaplastic thyroid cancer; PTC, papillary thyroid cancer; TERT, telomerase reverse transcriptase. aStaging according to the American Joint Committee on Cancer (AJCC) Thyroid Cancer Staging System 2009 (Edge et al. 2010).

(Sohn et al. 2016). First-round PCR was performed using primers TERT-F and TERT-236-R as described previously (Liu et al. 2013). The $235 \mathrm{bp}$-sized PCR amplicon was subjected to second-round PCR using primers TERT-F and TERT-163-R (Horn et al. 2013). The primer sequences for
TERT mutations are presented in Supplementary Table 1, see section on supplementary data given at the end of this article. PCRs were performed using a GeneAmp PCR system 9700 thermal cycler (Applied Biosystems). Cycle sequencing was performed using Big Dye Terminator Cycle Sequencing Ready Reaction kits (Applied Biosystems) on an ABI 3730xl Genetic Analyzer (Applied Biosystems).

\section{Detection of BRAF T1799A mutation}

Mutant enrichment with 3'-modified oligonucleotidesPCR (MEMO-PCR) and direct sequencing were performed as described previously (Lee et al. 2012). The obtained sequences were analyzed using the Sequencher program (Gene Codes Corp, Ann Arbor, MI, USA) and compared with a reference sequence (GenBank accession number NM_004333.4).

\section{Target exome sequencing (including TERT promoter and $B R A F$ )}

Genomic DNA (250ng) was sheared by Covaris S220 (Covaris, Woburn, MA, USA) and was used for the construction of a library using targeted exome sequencing (CancerSCAN) probes and SureSelect XT reagent kit, HSQ (Agilent Technologies) according to the manufacturers' protocols. CancerSCAN probes cover the TERT promoter region and whole exons of 381 genes, including $B R A F$. After enriched exome libraries were multiplexed, the libraries were sequenced on HiSeq 2500 sequencing platform (Illumina, San Diego, CA, USA). Briefly, a pairedend DNA sequencing library was prepared through genomic DNA shearing, end-repair, A-tailing, paired-end adaptor ligation and amplification. After hybridization of the library with bait sequences for $16 \mathrm{~h}$, the captured library was purified and amplified with an index barcode tag, and the library quality and quantity were measured. Sequencing of the exome library was carried out using the 100 bp paired-end mode of the TruSeq Rapid PE Cluster kit and TruSeq Rapid SBS kit (Illumina).

\section{Statistical analysis}

We used univariate logistic regression analyses to evaluate the association of TERT promoter mutation status with conventional clinical and pathological variables (Table 2). We investigated the association between clinicopathological variables, TERT and BRAF mutation status with thyroid cancer-specific survival, defined as the time from the initial surgical treatment to thyroid

Published by Bioscientifica Ltd 
Table 2 Association of TERT mutation status with clinicopathological variables in 409 thyroid cancer patients.

\begin{tabular}{|c|c|c|c|c|c|}
\hline Variables & TERT WT $(N(\%))$ & TERT mut $(N(\%))$ & Total & OR $^{\mathbf{a}}(95 \% \mathrm{Cl})$ & $P$ value \\
\hline \multicolumn{6}{|l|}{ Sex } \\
\hline Female & 297 (87.6) & $42(12.4)$ & 339 & 1.00 (referent) & 0.82 \\
\hline Male & $62(88.6)$ & $8(11.4)$ & 70 & $0.91(0.41-2.04)$ & \\
\hline \multicolumn{6}{|l|}{ Age } \\
\hline Per 5 year & & & 409 & $1.96(1.64-2.36)$ & $<0.001$ \\
\hline$<45$ & 222 (98.2) & $4(1.8)$ & 226 & 1.00 (referent) & $<0.001$ \\
\hline$\geq 45$ & 137 (74.9) & $46(25.1)$ & 183 & $18.64(6.56-52.92)$ & \\
\hline \multicolumn{6}{|l|}{$B R A F$ mutation } \\
\hline WT & 109 (90.1) & $12(9.9)$ & 121 & 1.00 (referent) & 0.43 \\
\hline Mutant & $176(87.1)$ & 26 (12.9) & 202 & $1.34(0.65-2.77)$ & \\
\hline Missing data & $74(86.0)$ & $12(14.0)$ & 86 & & \\
\hline \multicolumn{6}{|c|}{ Histological type } \\
\hline PTC & $295(90.2)$ & $32(9.8)$ & 327 & 1.00 (referent) & 0.001 \\
\hline FTC & 55 (83.3) & $11(16.7)$ & 66 & $1.84(0.88-3.88)$ & \\
\hline PDTC/ATC & $9(56.3)$ & 7 (43.8) & 16 & 7.17 (2.50-20.55) & \\
\hline \multicolumn{6}{|l|}{ Multifocality } \\
\hline Absent & $263(88.0)$ & $36(12.0)$ & 299 & 1.00 (referent) & 0.85 \\
\hline Present & 96 (87.3) & $14(12.7)$ & 110 & $1.07(0.55-2.06)$ & \\
\hline \multicolumn{6}{|c|}{ Lymph node metastasis } \\
\hline Absent & $184(89.3)$ & $22(10.7)$ & 206 & 1.00 (referent) & 0.39 \\
\hline Present & $174(86.6)$ & $27(13.4)$ & 201 & $1.30(0.71-2.36)$ & \\
\hline Missing data & $1(50.0)$ & $1(50.0)$ & 2 & & \\
\hline \multicolumn{6}{|c|}{ Extrathyroidal invasion } \\
\hline Absent & $105(94.6)$ & $6(5.4)$ & 111 & 1.00 (referent) & 0.01 \\
\hline Present & $211(85.1)$ & 37 (14.9) & 248 & $3.07(1.26-7.50)$ & \\
\hline Missing data & $43(86.0)$ & 7 (14.0) & 50 & & \\
\hline \multicolumn{6}{|c|}{ Distant metastasis } \\
\hline Absent & $342(89.1)$ & $42(10.9)$ & 384 & 1.00 (referent) & 0.003 \\
\hline Present & $17(68.0)$ & $8(32.0)$ & 25 & $3.83(1.56-9.42)$ & \\
\hline \multicolumn{6}{|c|}{ Stage at diagnosisb } \\
\hline I & $216(97.3)$ & $6(2.7)$ & 222 & 1.00 (referent) & $<0.001$ \\
\hline II & $25(96.2)$ & $1(3.8)$ & 26 & $1.44(0.17-12.45)$ & \\
\hline III & $91(88.3)$ & $12(11.7)$ & 103 & 4.75 (1.73-13.04) & \\
\hline IV & $27(46.6)$ & $31(53.4)$ & 58 & 41.33 (15.80-108.10) & \\
\hline \multicolumn{6}{|l|}{ Tumor size } \\
\hline$<2.0 \mathrm{~cm}$ & $41(91.1)$ & $4(8.9)$ & 45 & 1.00 (referent) & 0.08 \\
\hline $2.0-4.0 \mathrm{~cm}$ & 269 (89.1) & 33 (10.9) & 302 & $1.26(0.42-3.73)$ & \\
\hline$>4.0 \mathrm{~cm}$ & 49 (79.0) & $13(21.0)$ & 62 & $2.72(0.82-8.98)$ & \\
\hline
\end{tabular}

$B R A F$, v-Raf murine sarcoma viral oncogene homolog B; FTC, follicular thyroid cancer; PDTC/ATC, poorly differentiated/anaplastic thyroid cancer; PTC, papillary thyroid cancer; TERT, telomerase reverse transcriptase.

aThe odds ratio (OR) represents the odds for being a TERT promoter mutation carrier as compared with a TERT promoter wild-type carrier;

bStaging according to the American Joint Committee on Cancer (AJCC) Thyroid Cancer Staging System 2009 (Edge et al. 2010).

cancer-related mortality. Cases in which the end point was not reached at the time of the last follow-up were censored.

Survival analyses were focused on patients with differentiated thyroid cancer (PTC and FTC) because PDTC/ATC is uncommon and highly lethal. Univariate results were displayed using the Kaplan-Meier method, and hazard estimates and $P$ values were calculated from Cox proportional hazard models. For univariate analyses of $B R A F$ mutation, we used only cases with $B R A F$ mutation status available. Because the effect of $B R A F$ mutation was not significant in the univariate analyses, $B R A F$ mutation was not included in multivariate analyses.
As 'Stage at diagnosis' is a composite variable, we decided to separate the variable into its components ('Age', 'Extrathyroidal invasion', 'Distant metastasis' and 'Tumor size') in some of the multivariate analyses. In the extended model, all main effects with univariate $P$ values less than 0.20 , except 'Stage at diagnosis', were evaluated simultaneously (Tables 3 and 4, model 1). In the restricted model, the 'Stage at diagnosis' variable replaced its components to avoid overfitting (Tables 3 and 4, model 2). The model diagnostic included both graphical and formal Schoenfeld residual checks of the proportional hazards assumptions (Harrell et al. 1996). We conducted

Published by Bioscientifica Ltd 
Table 3 Association of TERT mutation status and clinicopathological variables with thyroid cancer-specific survival in 393 differentiated thyroid cancer patients.

\begin{tabular}{|c|c|c|c|c|c|c|c|c|}
\hline \multirow[b]{2}{*}{ Variables } & \multirow[b]{2}{*}{$\mathbf{N a}$} & \multirow{2}{*}{$\begin{array}{l}\text { 10-year } \\
\text { survival } \\
\text { rate }(\%)\end{array}$} & \multicolumn{2}{|c|}{ Univariate Cox models } & \multicolumn{2}{|c|}{$\begin{array}{c}\text { Multivariate Cox model } \mathbf{1 b} \\
\text { (extended model) }\end{array}$} & \multicolumn{2}{|c|}{$\begin{array}{c}\text { Multivariate Cox model 2c } \\
\text { (restricted model) }\end{array}$} \\
\hline & & & $\mathrm{HR}(95 \% \mathrm{Cl})$ & $P$ value & $\mathrm{HR}(95 \% \mathrm{Cl})$ & $P$ value & HR $(95 \% \mathrm{Cl})$ & $P$ value \\
\hline \multicolumn{9}{|l|}{ Sex } \\
\hline Female & 329 & 95.4 & 1.00 (referent) & 0.31 & & & & \\
\hline Male & 64 & 92.0 & $1.60(0.64-3.99)$ & & & & & \\
\hline \multicolumn{9}{|l|}{ Age $^{d}$} \\
\hline Per 5 year & 393 & & $1.76(1.60-1.92)$ & $<0.001$ & $1.51(1.30-1.72)$ & $<0.001$ & & \\
\hline$<45$ & 223 & 99.1 & 1.00 (referent) & $<0.001$ & & & & \\
\hline$\geq 45$ & 170 & 89.3 & 17.23 (4.07-72.95) & & & & & \\
\hline \multicolumn{9}{|c|}{ TERT mutations } \\
\hline WT & 350 & 98.3 & 1.00 (referent) & $<0.001$ & 1.00 (referent) & 0.002 & 1.00 (referent) & $<0.001$ \\
\hline Mutant & 43 & 66.2 & $23.26(10.10-53.56)$ & & $5.19(1.87-14.44)$ & & 7.18 (2.77-18.59) & \\
\hline \multicolumn{9}{|c|}{$B R A F$ mutation } \\
\hline WT & 117 & 92.3 & 1.00 (referent) & 0.28 & & & & \\
\hline Mutant & 199 & 97.5 & $0.60(0.24-1.51)$ & & & & & \\
\hline \multicolumn{9}{|c|}{ Histological type } \\
\hline PTC & 327 & 96.9 & 1.00 (referent) & 0.002 & 1.00 (referent) & 0.004 & 1.00 (referent) & $<0.001$ \\
\hline FTC & 66 & 84.8 & $3.24(1.47-7.15)$ & & $9.27(2.06-41.72)$ & & $4.94(2.09-11.68)$ & \\
\hline \multicolumn{9}{|l|}{ Multifocality } \\
\hline Absent & 286 & 94.7 & 1.00 (referent) & 0.98 & & & & \\
\hline Present & 107 & 95.3 & $0.99(0.42-2.36)$ & & & & & \\
\hline \multicolumn{9}{|c|}{ Lymph node metastasis } \\
\hline Absent & 199 & 94.4 & 1.00 (referent) & 0.91 & & & & \\
\hline Present & 193 & 95.3 & $0.96(0.44-2.10)$ & & & & & \\
\hline \multicolumn{9}{|c|}{ Extrathyroidal invasion } \\
\hline Absent & 108 & 98.1 & 1.00 (referent) & 0.11 & 1.00 (referent) & 0.04 & & \\
\hline Present & 239 & 94.9 & $2.70(0.79-9.22)$ & & $5.16(1.06-24.99)$ & & & \\
\hline \multicolumn{9}{|c|}{ Distant metastasis } \\
\hline Absent & 373 & 96.5 & 1.00 (referent) & $<0.001$ & 1.00 (referent) & 0.23 & & \\
\hline Present & 20 & 65.0 & $8.66(3.63-20.64)$ & & $1.89(0.67-5.31)$ & & & \\
\hline \multicolumn{9}{|c|}{ Stage at diagnosise } \\
\hline I & 218 & 99.1 & 1.00 (referent) & $<0.001$ & & & 1.00 (referent) & 0.003 \\
\hline II & 26 & 92.3 & $8.18(1.15-58.11)$ & & & & $4.58(0.63-33.33)$ & \\
\hline III & 103 & 97.1 & $6.92(1.40-34.32)$ & & & & $6.53(1.26-33.84)$ & \\
\hline IV & 46 & 71.0 & 47.09 (10.81-205.09) & & & & 18.28 (3.58-93.25) & \\
\hline \multicolumn{9}{|l|}{ Tumor size } \\
\hline$<2.0 \mathrm{~cm}$ & 45 & 95.4 & 1.00 (referent) & 0.03 & 1.00 (referent) & 0.04 & & \\
\hline $2.0-4.0 \mathrm{~cm}$ & 293 & 96.2 & $1.20(0.28-5.23)$ & & $0.72(0.16-3.37)$ & & & \\
\hline$>4.0 \mathrm{~cm}$ & 55 & 87.0 & $3.58(0.76-16.84)$ & & $2.52(0.49-13.14)$ & & & \\
\hline
\end{tabular}

$B R A F$, v-Raf murine sarcoma viral oncogene homolog B; FTC, follicular thyroid cancer; PTC, papillary thyroid cancer; TERT, telomerase reverse transcriptase.

aThe number of available data for a particular variable in the univariate analysis; b Extended model in which all predictors with univariate $P$ values $\leq 0.20$, except 'Stage at diagnosis', are included; no interactions were considered; 'Restricted model that includes 'TERT mutations', 'Histological type' and 'Stage at diagnosis'; no interactions were considered; 'Multivariate Cox regression analysis results for 'Age' are analyzed and presented for the continuous linear variable; eStaging according to the American Joint Committee on Cancer (AJCC) Thyroid Cancer Staging System 2009 (Edge et al. 2010 ).

a sensitivity analysis by applying a backward elimination approach to a multivariate Cox regression including all the univariate explanatory variables.

In addition, we performed subgroup analysis for patients with PTC, the most common histological type. All $P$ values were two sided, and a $P$ value $<0.05$ was treated as statistically significant. All statistical analyses were performed using SPSS statistical software (version 21.0; SPSS).

\section{Results}

\section{Clinical evaluation}

In total, 421 thyroid cancer samples were screened for the study. The further analyzed cohort consisted of samples from 409 patients whose TERT promoter sequencing of tumor DNA was successful. There were 339 women and 70 men with a median age of 44 years (range 16-81 years) and a median follow-up duration of 13 years

Published by Bioscientifica Ltd 
Table 4 Association of TERT mutation status and clinicopathological variables with thyroid cancer-specific survival in 327 papillary thyroid cancer patients.

\begin{tabular}{|c|c|c|c|c|c|c|c|c|}
\hline \multirow[b]{2}{*}{ Variables } & \multirow[b]{2}{*}{$\mathbf{N a}$} & \multirow{2}{*}{$\begin{array}{l}\text { 10-year } \\
\text { survival } \\
\text { rate }(\%)\end{array}$} & \multicolumn{2}{|c|}{ Univariate Cox models } & \multicolumn{2}{|c|}{$\begin{array}{l}\text { Multivariate Cox model } \mathbf{1 b}^{\mathbf{b}} \\
\text { (extended model) }\end{array}$} & \multicolumn{2}{|c|}{$\begin{array}{l}\text { Multivariate Cox model 2c } \\
\text { (restricted model) }\end{array}$} \\
\hline & & & HR $(95 \% \mathrm{Cl})$ & $P$ value & HR $(95 \% \mathrm{Cl})$ & $P$ value & $\mathrm{HR}(95 \% \mathrm{Cl})$ & $P$ value \\
\hline \multicolumn{9}{|l|}{ Sex } \\
\hline Female & 276 & 97.8 & 1.00 (referent) & 0.07 & 1.00 (referent) & 0.56 & 1.00 (referent) & 0.21 \\
\hline Male & 51 & 92.0 & $2.62(0.91-7.56)$ & & $1.50(0.38-5.99)$ & & $2.00(0.68-5.84)$ & \\
\hline \multicolumn{9}{|l|}{ Age $^{d}$} \\
\hline Per 5 year & 327 & & $1.74(1.54-1.94)$ & $<0.001$ & 1.33 (1.06-1.59) & 0.04 & & \\
\hline$<45$ & 187 & 98.9 & 1.00 (referent) & 0.002 & & & & \\
\hline$\geq 45$ & 140 & 94.2 & $10.21(2.32-44.99)$ & & & & & \\
\hline \multicolumn{9}{|c|}{ TERT mutations } \\
\hline WT & 295 & 99.3 & 1.00 (referent) & $<0.001$ & 1.00 (referent) & 0.001 & 1.00 (referent) & 0.001 \\
\hline Mutant & 32 & 74.2 & $33.38(10.76-103.61)$ & & $10.78(2.67-43.51)$ & & $14.20(3.03-66.68)$ & \\
\hline \multicolumn{9}{|c|}{ BRAF mutation } \\
\hline WT & 65 & 98.5 & 1.00 (referent) & 0.28 & & & & \\
\hline Mutant & 199 & 97.5 & $3.12(0.39-24.60)$ & & & & & \\
\hline \multicolumn{9}{|l|}{ Multifocality } \\
\hline Absent & 228 & 97.3 & 1.00 (referent) & 0.50 & & & & \\
\hline Present & 99 & 95.9 & $1.41(0.51-3.89)$ & & & & & \\
\hline \multicolumn{9}{|c|}{ Lymph node metastasis } \\
\hline Absent & 136 & 97.8 & 1.00 (referent) & 0.48 & & & & \\
\hline Present & 190 & 96.3 & $1.47(0.50-4.30)$ & & & & & \\
\hline \multicolumn{9}{|c|}{ Extrathyroidal invasion } \\
\hline Absent & 73 & 100.0 & 1.00 (referent) & 0.13 & 1.00 (referent) & 0.27 & & \\
\hline Present & 233 & 95.7 & $4.85(0.64-36.72)$ & & $3.45(0.39-30.66)$ & & & \\
\hline \multicolumn{9}{|c|}{ Distant metastasis } \\
\hline Absent & 314 & 97.4 & 1.00 (referent) & 0.09 & 1.00 (referent) & 0.78 & & \\
\hline Present & 13 & 84.6 & $3.66(0.83-16.13)$ & & $1.32(0.19-8.93)$ & & & \\
\hline \multicolumn{9}{|c|}{ Stage at diagnosise } \\
\hline I & 178 & 98.9 & 1.00 (referent) & $<0.001$ & & & 1.00 (referent) & 0.64 \\
\hline II & 17 & 100.0 & NA & & & & NA & \\
\hline III & 95 & 98.9 & $4.14(0.76-22.62)$ & & & & $2.04(0.31-13.35)$ & \\
\hline IV & 37 & 80.4 & $27.94(6.12-127.64)$ & & & & $3.61(0.47-27.47)$ & \\
\hline \multicolumn{9}{|l|}{ Tumor size } \\
\hline$<2.0 \mathrm{~cm}$ & 35 & 97.1 & 1.00 (referent) & 0.20 & 1.00 (referent) & 0.14 & & \\
\hline $2.0-4.0 \mathrm{~cm}$ & 253 & 97.6 & $1.46(0.19-11.32)$ & & $0.84(0.10-6.82)$ & & & \\
\hline$>4.0 \mathrm{~cm}$ & 39 & 92.1 & $3.91(0.44-35.03)$ & & $3.37(0.34-33.73)$ & & & \\
\hline
\end{tabular}

$B R A F$, v-Raf murine sarcoma viral oncogene homolog $B ;$ TERT, telomerase reverse transcriptase.

aThe number of available data for a particular variable in the univariate analysis; ${ }^{b}$ Extended model in which all predictors with univariate $P$ values $\leq 0.20$, except 'Stage at diagnosis', are included; no interactions were considered; 'Restricted model that includes 'Sex', 'TERT mutations' and 'Stage at diagnosis'; no interactions were considered; dMultivariate Cox regression analysis results for 'Age' are analyzed and presented for the continuous linear variable; eStaging according to the American Joint Committee on Cancer (AJCC) Thyroid Cancer Staging System 2009 (Edge et al. 2010).

(interquartile range 11-16 years). There were cumulative deaths in 5.5\% (18/327) of PTC, $18.2 \%(12 / 66)$ of FTC and $75.0 \%(12 / 16)$ of PDTC/ATC patients. Most of these deaths were related to thyroid cancer. Specifically, $4.9 \%$ $(16 / 327)$ of PTC, $15.2 \%(10 / 66)$ of FTC and $75.0 \%(12 / 16)$ of PDTC/ATC cases resulted in a thyroid cancer-related death. The baseline clinical data and mutation status of the tumors are presented in Table 1.

\section{Mutational analysis}

The TERT promoter was successfully PCR amplified and sequenced in 409 patients (327 PTC, 66 FTC and
16 PDTC/ATC). Recurrent mutations were located at previously described hotspots: chr.5:1,295,228C $>\mathrm{T}$ and chr.5:1,295,250C>T. The TERT promoter region showed mutant reads in $9.8 \%(32 / 327)$ of PTC, $16.7 \%(11 / 66)$ of FTC and $43.8 \%$ (7/16) of PDTC/ATC patients: the majority of the mutations were $228 \mathrm{C}>\mathrm{T}$, and $250 \mathrm{C}>\mathrm{T}$ was found in three PTC and one FTC patients. Sequencing for $B R A F$ was successful in 323 (79.0\%) patients. The BRAF T1799A mutation was observed in $75.4 \%$ (199/264) of PTC, 0\% (0/52) of FTC and 42.9\% (3/7) of PDTC/ATC patients. For validation of the TERT promoter and $B R A F$ genotyping results, we also performed high-coverage cancer panel sequencing in a randomly selected subset of TERT

Published by Bioscientifica Ltd 
promoter mutation-positive $(n=2)$ and -negative cases $(n=8)$. The results obtained by two different methods were identical in all selected cases (Supplementary Fig. 1A, B and Supplementary Table 2).

\section{Association of TERT promoter mutation status with clinicopathological variables}

TERT promoter mutations were significantly more common in older patients $(P<0.001)$, in tumors with extrathyroidal invasion $(P=0.01)$, in cases with distant metastasis $(P=0.003)$ and with increased stage at diagnosis $(P<0.001)$ (Table 2$)$. The TERT mutation frequencies differed among histological type $(9.8 \%$ in PTC, $16.7 \%$ in FTC and $43.8 \%$ in PDTC/ATC; $P=0.001$ for the frequency difference). Separate data for patients with differentiated thyroid cancer are presented in Supplementary Table 3. In patients with PTC, the largest subgroup, TERT promoter mutations were more common in the mutant BRAF than the wild type $(12.1 \%(24 / 199)$ vs $3.1 \%(2 / 65) ; P=0.03)$.

\section{Association of TERT promoter mutation status and clinicopathological variables with thyroid cancer-related mortality}

Survival analyses were performed for patients with differentiated thyroid cancer (Fig. 1A and Table 3) and for patients with PTC (Fig. 1B and Table 4). In differentiated thyroid cancer patients (Table 3), univariate predictors of survival were TERT promoter mutation status $(P<0.001)$, patient age $(P<0.001)$, histological type (poorer in FTC compared with PTC; $P=0.002)$, distant metastasis $(P<0.001)$, stage at diagnosis $(P<0.001)$ and tumor size $(P=0.03)$. Patients with mutant TERT promoter tumors showed worse prognosis (10-year survival rate of $66.2 \%$, compared with $98.3 \%$ for wild-type tumors). In multivariate analysis, however, the adjusted HRs (95\% CI) were differently estimated according to variable selection strategy (5.19 (1.87-14.44), $P=0.002$ for the extended model; 7.18 (2.77-18.59), $P<0.001$ for the restricted model). In addition, patient age, histological type, extrathyroidal invasion, stage at diagnosis and tumor size were independent factors.

In patients with PTC (Table 4), factors that were significantly associated with poorer survival in univariate analyses included TERT promoter mutations $(P<0.001)$, increased age $(P<0.001)$ and increased stage at diagnosis (in particular stage IV, compared with lower stage; $P<0.001)$. Multivariate analysis showed that TERT
A

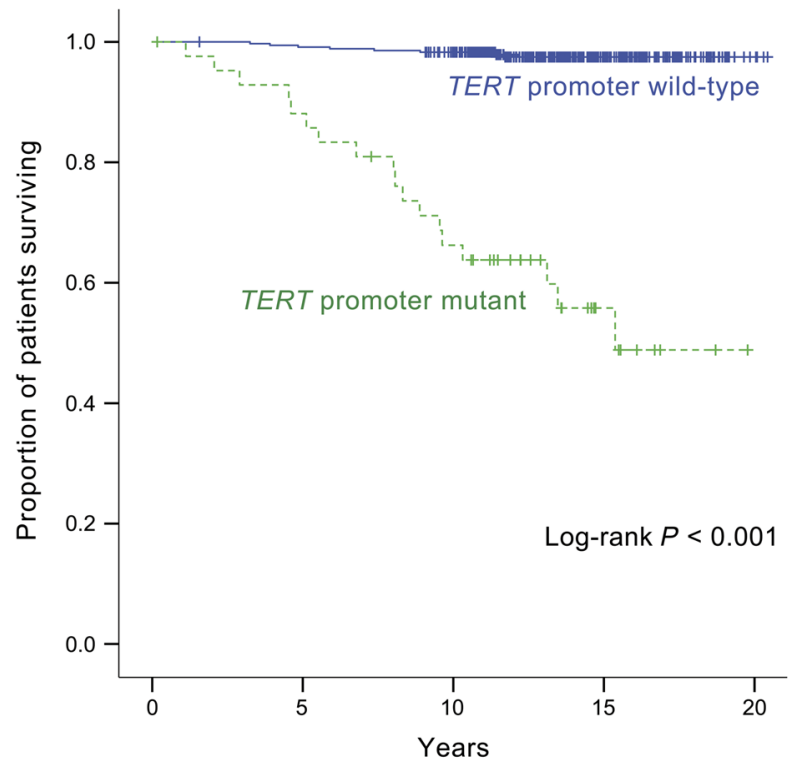

No. at risk

$\begin{array}{lccccc}\text { TERT WT } & 350 & 346 & 329 & 112 & 4 \\ \text { TERT MUT } & 43 & 37 & 27 & 8 & 0\end{array}$

B

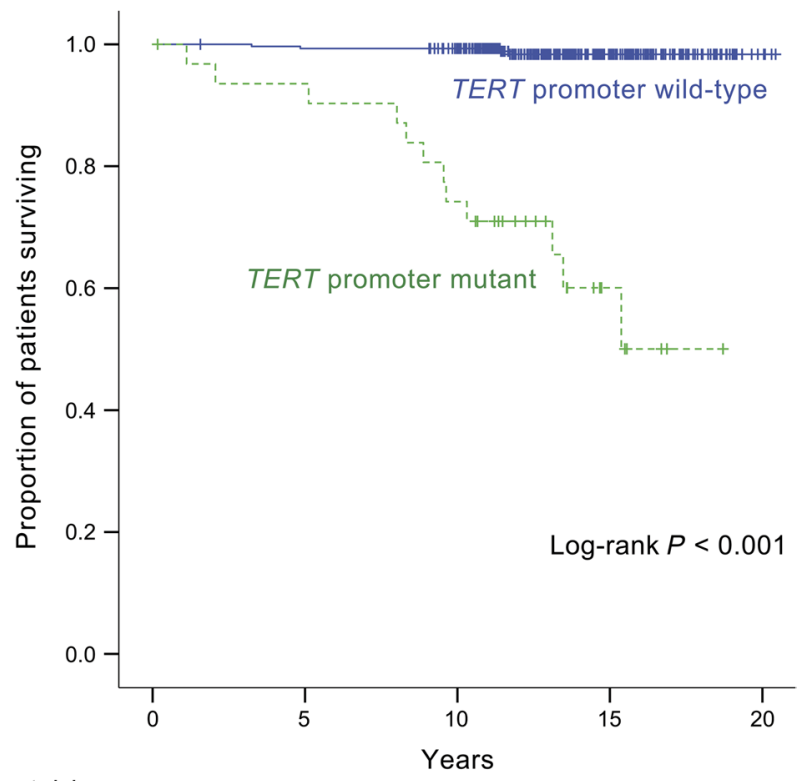

No. at risk

$\begin{array}{lccccc}\text { TERT WT } & 295 & 292 & 280 & 92 & 4 \\ \text { TERT MUT } & 32 & 29 & 23 & 6 & 0\end{array}$

Figure 1

Kaplan-Meier curves of thyroid cancer-specific survival by TERT mutational status. Results from the analysis of patients with (A) differentiated thyroid cancer and (B) papillary thyroid cancer. A full colour version of this figure is available at http://dx.doi.org/10.1530/ERC-16-0219.

promoter mutations $(P=0.001)$ and increased age $(P=0.04)$ were independently associated with poorer survival. In the restricted model, the estimated adjusted HR (95\% CI)

Published by Bioscientifica Ltd 
was 14.20 (3.03-66.68) for the mutant TERT promoter compared with the wild type, and stage at diagnosis was no longer a significant predictor of survival.

In a sensitivity analysis with backward elimination approach, the models included TERT mutations that are presented in Table 3 (TERT mutations with histological type and extrathyroidal invasion) and also in Table 4 (TERT mutations only). HRs for TERT mutations were 14.33 (4.81-42.71) and 39.47 (8.38-185.99) (Tables 3 and 4). Although these HRs differed from those in other models, they were contained within 95\% CIs of HR in all other models; and their 95\% CIs contained HRs in all other models.

For patients with PTC, we performed stratified analysis of four genotypes according to the TERT and $B R A F$ mutational status. The Kaplan-Meier analysis (Fig. 2) shows significant difference in survival in relation to the genotypes (log-rank $P<0.001$ ). There were no deceased cases in either wild type. The 10-year survival rates among the $B R A F$ mutation only and concomitant TERT and BRAF mutations were 99.4\% and $82.6 \%$, respectively. TERT promoter mutations in addition to BRAF mutation significantly worsened PTC patient survival: when the genotypes replaced the "TERT mutations" variable in the extended and the

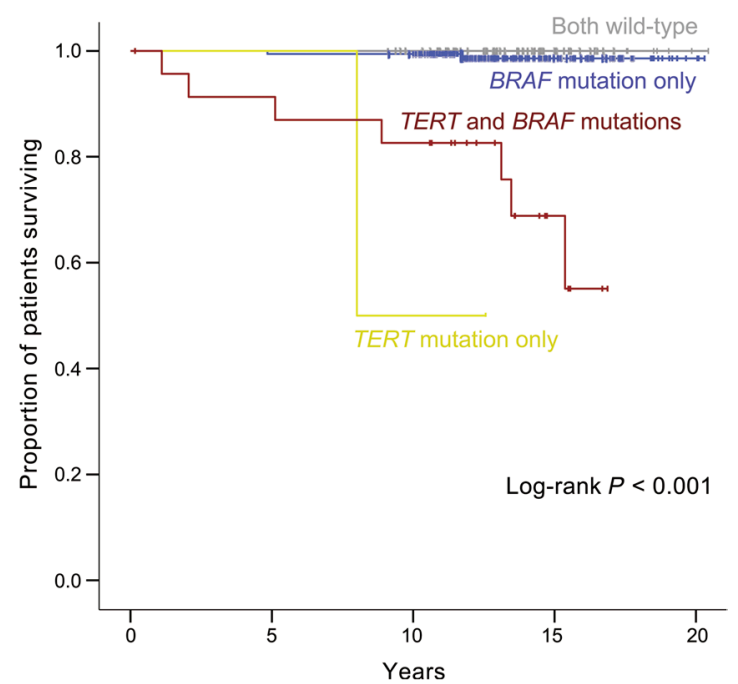

No. at risk

$\begin{array}{lccccc}\text { Both WT } & 63 & 63 & 59 & 21 & 0 \\ \text { BRAF MUT only } & 175 & 174 & 170 & 47 & 3 \\ \text { TERT MUT only } & 2 & 2 & 1 & 0 & 0 \\ \text { TERT and BRAF MUT } 24 & 21 & 19 & 5 & 0\end{array}$

Figure 2

Kaplan-Meier curves of thyroid cancer-specific survival by four genotypes according to the TERT and BRAF mutational status. Results from the analysis of patients with papillary thyroid cancer. A full colour version of this figure is available at http://dx.doi.org/10.1530/ERC-16-0219. restricted models (Table 4), the adjusted HRs (95\% CI) were 2.77 (1.15-6.65), $P=0.02$ for the former model and 5.62 (1.85-17.09), $P=0.002$ for the latter model.

\section{Discussion}

In this study, we found recurrent TERT promoter mutations in $9.8 \%$ of PTC, $16.7 \%$ of FTC and $43.8 \%$ of PDTC/ ATC patients. In analyses of both differentiated thyroid cancer and PTC patients, the presence of TERT promoter mutations was found to be a marker of poor survival and remained significant on multivariate adjustment for conventional clinicopathological risk factors and for stage. The absence of the mutations conferred negligible mortality risk during long-term follow-up in PTC patients.

This study is notable because of the inclusion of a large cohort of thyroid cancer patients with robust clinicopathological data and adequate follow-up period (median 13 years), which is essential to evaluate the final outcome of a slowly progressing cancer with distinctively low mortality such as thyroid cancer (Kim et al. 2012). The results obtained here demonstrated that TERT promoter mutation status could be an independent prognostic marker in differentiated thyroid cancer for the outcome of long-term mortality, as suggested by preexisting studies (Landa et al. 2013, Liu et al. 2013, 2014a,b, Vinagre et al. 2013, Melo et al. 2014, Xing et al. 2014b). We observed that the point estimates for the HR for TERT varied across the models (i.e., extended, restricted and backward elimination based) as the HR was conditional on the variables selected in each model. Also, because mutant TERT is not very common, the HR was not estimated very precisely. Nevertheless, the independent effect of TERT mutations was demonstrated in all models, including the backward elimination-based model.

Cell immortalization is the step that is thought to be a prerequisite for the development of all human cancers; however, the exact mechanism of telomere stabilization had remained elusive. The discovery of TERT promoter mutations (-124C>T (C228T) and -146C $>\mathrm{T}$ (C250T)) (Horn et al. 2013, Huang et al. 2013) out of the noncoding region (so-called dark matter) of the human genome provided new mechanistic insight for telomere activation, particularly in tumors originating from tissues with a relatively low rate of self-renewal, such as glioma (Killela et al. 2013), bladder cancer (Hurst et al. 2014) and thyroid cancer (Liu et al. 2013). The mutations generate de novo consensus binding motifs for mitogen-activated protein kinase (MAPK)-dependent E26 transformationspecific (ETS) transcription factor (Strahl et al. 1996,

Published by Bioscientifica Ltd 
Horn et al. 2013, Huang et al. 2013). This mechanism is relevant in thyroid cancer as the majority of cases are driven by activation of the RAS-MAPK pathway via point mutations (BRAF and RAS) (The Cancer Genome Atlas Research Network 2014) or chromosomal rearrangements (RET/PTC (Nikiforov 2002), AKAP9/BRAF (Ciampi et al. 2005) and TRK (Russell et al. 2000)); therefore, it is expected that ETS transcription factors are highly activated. Mutant TERT promoters in thyroid cancer were responsible for the increased expression of the enzymatic subunit of the telomere holoenzyme (Muzza et al. 2015), resulting in the maintenance of chromosomal stability in proliferative cancer cells without control by apoptosis or senescence (Gunes \& Rudolph 2013).

Most of the known associations among conventional clinicopathological variables and TERT promoter mutations were reproduced in this study, supporting our findings (Table 2 and Supplementary Table 3) (Liu et al. 2013, 2014a, Melo et al. 2014). In particular, the mutation frequency detected in differentiated thyroid cancers was about $11 \%$, whereas the frequency increased to $44 \%$ in PDTC/ATC patients. As progressive dedifferentiation of PTC and FTC gives rise to PDTC and ATC, the close relationship between TERT promoter mutations and thyroid differentiation status may be one of the key biological mechanisms for the causal association between TERT promoter mutations and poor survival of patients even in cases morphologically classified as differentiated thyroid cancer. This relationship is consistent with in vitro evidence showing that the suppression of telomerase activity in melanoma cell lines induced cellular differentiation and reduced metastasis (Bagheri et al. 2006) or, vice-versa, the induction of differentiation leads to the downregulation of telomerase activity in immortalized cell lineages and embryonic stem cells (Sharma et al. 1995). In histological subgroup analysis of our data, survival differences based on TERT promoter mutational status were evident in PTC (Fig. 1B) and FTC (Supplementary Fig. 2A), but fell short of significance in already dedifferentiated cancers (Supplementary Fig. 2B). It is worth noting that the number of cases analyzed for dedifferentiated cancers was small compared with the number for PTC and FTC and that may be the reason for the lack of significance. A recent study of 106 patients with anaplastic thyroid cancer found an association of TERT C228T with BRAF T1799A mutations, older patient age and distant metastasis (Shi et al. 2015).

We observed that TERT promoter mutations were more common in PTC patients with the BRAF T1799A mutation, as suggested by some previous reports (Liu et al. 2013, Melo et al. 2014), but not all (Landa et al. 2013, Muzza et al. 2015). An American study including 507 patients who were treated for PTC from 1990 to 2012 at Johns Hopkins Hospital reported that a combination of the TERT C228T and BRAF T1799A mutations was associated with a high risk of early recurrence (Xing et al. $2014 b$ ). On the contrary, a recent Italian study reported that neither BRAF nor RAS mutations had additional effects on disease persistence in patients with PTC and FTC (Muzza et al. 2015). However, the number of cases with coexisting mutations in the latter study was too small to reach statistically meaningful conclusion. In stratified analysis of our data of PTC, the vast majority of TERT promoter mutations occurred on a background of $B R A F$ mutation. This coexistence significantly worsens PTC patient survival compared with having BRAF mutation alone, supporting the notion that the aggressiveness of TERT mutations is in fact largely from the synergy of coexisting genetic abnormalities that activate the RASMAPK pathway, particularly BRAF and RAS mutations (Ngeow \& Eng 2014, Xing et al. 2014b, Song et al. 2016, Xing 2016). A previous large study on the role of TERT mutations on the mortality of PTC also supports this interaction (Xing et al. 2014a).

There are several limitations to this study. This was a retrospective study and was thus prone to selection bias. An independent prospectively collected cohort with long-term follow-up will be needed to validate the study results. As the samples were collected before the era of widespread ultrasonographic screening for indolent thyroid cancer (Brito et al. 2013, Vaccarella et al. 2015), this cohort contained a low number of small tumors (11\% of cases were smaller than $2 \mathrm{~cm}$ ) and most of the cases presented with palpable neck mass. The inclusion of larger tumors might exaggerate the frequency of TERT promoter mutations in a given sample population, as the reported frequency in micro-PTC was only $4.7 \%$ (de Biase et al. 2015). Therefore, caution is necessary when applying the mutations as a prognostic biomarker to a different population, particularly for individuals with ultrasounddetected small micro-PTC. TERT mutations can coexist with RAS mutations as demonstrated previously (Muzza et al. 2015, Song et al. 2016) and as shown by two cases in Supplementary Table 2 (KRAS Q61R and NRAS Q61R). We could not develop more sophisticated models for FTC and PTC with wild-type BRAF using RAS mutations because of the small sample size of these subgroups with sufficient long-term follow-up. 
In conclusion, the presence of TERT promoter mutations was found to be an independent marker of poor survival in differentiated thyroid cancer in our patient cohort. The absence of the mutations conferred negligible mortality risk during long-term follow-up in PTC patients. We predicted that the inclusion of TERT promoter mutation analysis with conventional clinicopathological evaluation could markedly improve the prognostication and management of individual patients with differentiated thyroid cancer.

\section{Supplementary data}

This is linked to the online version of the paper at http://dx.doi.org/10.1530/ ERC-16-0219.

\section{Declaration of interest}

The authors declare that there is no conflict of interest that could be perceived as prejudicing the impartiality of the research reported.

\section{Funding}

This research was supported by Korean Foundation for Cancer Research grant (grant number CB-2011-03-02).

\section{Acknowledgements}

The authors would like to thank Dr Alice Hyun-Kyung Tan (Samsung Medical Center, Seoul, Korea) for improving the use of English in the manuscript and Drs Chan Kwon Jung (Catholic University, Seoul, Korea) and Young Suk Jo (Yonsei University, Seoul, Korea) for materials and for the development of the TERT promoter mutation analysis platform.

\section{References}

Bagheri S, Nosrati M, Li S, Fong S, Torabian S, Rangel J, Moore DH, Federman S, Laposa RR, Baehner FL, et al. 2006 Genes and pathways downstream of telomerase in melanoma metastasis. PNAS $\mathbf{1 0 3}$ 11306-11311. (doi:10.1073/pnas.0510085103)

Brito JP, Morris JC \& Montori VM 2013 Thyroid cancer: zealous imaging has increased detection and treatment of low risk tumours. BMJ $\mathbf{3 4 7}$ f4706. (doi:10.1136/bmj.f4706)

Chen AY, Jemal A \& Ward EM 2009 Increasing incidence of differentiated thyroid cancer in the United States, 1988-2005. Cancer 115 3801-3807. (doi:10.1002/cncr.24416)

Ciampi R, Knauf JA, Kerler R, Gandhi M, Zhu Z, Nikiforova MN, Rabes HM, Fagin JA \& Nikiforov YE 2005 Oncogenic AKAP9-BRAF fusion is a novel mechanism of MAPK pathway activation in thyroid cancer. Journal of Clinical Investigation 115 94-101. (doi:10.1172/ jci23237)

Cooper DS, Doherty GM, Haugen BR, Kloos RT, Lee SL, Mandel SJ, Mazzaferri EL, McIver B, Sherman SI \& Tuttle RM 2006 Management guidelines for patients with thyroid nodules and differentiated thyroid cancer. Thyroid 16 109-142. (doi:10.1089/ thy.2006.16.109)

Cooper DS, Doherty GM, Haugen BR, Kloos RT, Lee SL, Mandel SJ, Mazzaferri EL, McIver B, Pacini F, Schlumberger M, et al. 2009
Revised American Thyroid Association management guidelines for patients with thyroid nodules and differentiated thyroid cancer. Thyroid 19 1167-1214. (doi:10.1089/thy.2009.0110)

de Biase D, Gandolfi G, Ragazzi M, Eszlinger M, Sancisi V, Gugnoni M, Visani M, Pession A, Casadei G, Durante C, et al. 2015 TERT promoter mutations in papillary thyroid microcarcinomas. Thyroid 25 1013-1019. (doi:10.1089/thy.2015.0101)

DeGroot LJ, Kaplan EL, McCormick M \& Straus FH 1990 Natural history, treatment, and course of papillary thyroid carcinoma. Journal of Clinical Endocrinology and Metabolism 71 414-424. (doi:10.1210/jcem71-2-414)

Edge SB, Byrd DR, Compton CC, Fritz AG, Greene FL, Trotti A \& American Joint Committee on Cancer 2010 AJCC Cancer Staging Manual. New York, NY, USA: Springer.

Gunes C \& Rudolph KL 2013 The role of telomeres in stem cells and cancer. Cell 152 390-393. (doi:10.1016/j.cell.2013.01.010)

Harrell FE Jr, Lee KL \& Mark DB 1996 Multivariable prognostic models: issues in developing models, evaluating assumptions and adequacy, and measuring and reducing errors. Statistics in Medicine 15 361-387. (doi:10.1002/(sici)1097-0258(19960229)15:4<361::aid-sim168 $>3.0 . \operatorname{co} 2-4)$

Hay ID, Bergstralh EJ, Goellner JR, Ebersold JR \& Grant CS 1993 Predicting outcome in papillary thyroid carcinoma: development of a reliable prognostic scoring system in a cohort of 1779 patients surgically treated at one institution during 1940 through 1989. Surgery 114 1050-1057.

Horn S, Figl A, Rachakonda PS, Fischer C, Sucker A, Gast A, Kadel S, Moll I, Nagore E, Hemminki K, et al. 2013 TERT promoter mutations in familial and sporadic melanoma. Science 339 959-961. (doi:10.1126/science.1230062)

Huang FW, Hodis E, Xu MJ, Kryukov GV, Chin L \& Garraway LA 2013 Highly recurrent TERT promoter mutations in human melanoma. Science 339 957-959. (doi:10.1126/science.1229259)

Hundahl SA, Fleming ID, Fremgen AM \& Menck HR 1998 A National Cancer Data Base report on 53,856 cases of thyroid carcinoma treated in the U.S., 1985-1995. Cancer 83 2638-2648. (doi:10.1002/(SICI)1097-0142(19981215)83:12<2638::AIDCNCR31>3.0.CO;2-1)

Hurst CD, Platt FM \& Knowles MA 2014 Comprehensive mutation analysis of the TERT promoter in bladder cancer and detection of mutations in voided urine. European Urology 65 367-369. (doi:10.1016/j.eururo.2013.08.057)

Killela PJ, Reitman ZJ, Jiao Y, Bettegowda C, Agrawal N, Diaz LA Jr, Friedman AH, Friedman H, Gallia GL, Giovanella BC, et al. 2013 TERT promoter mutations occur frequently in gliomas and a subset of tumors derived from cells with low rates of self-renewal. PNAS 110 6021-6026. (doi:10.1073/pnas.1303607110)

Kim TH, Park YJ, Lim JA, Ahn HY, Lee EK, Lee YJ, Kim KW, Hahn SK, Youn YK, Kim KH, et al. 2012 The association of the BRAF(V600E) mutation with prognostic factors and poor clinical outcome in papillary thyroid cancer: a meta-analysis. Cancer 118 1764-1773. (doi:10.1002/cncr.26500)

Kim S, Lee J, Hong ME, Do IG, Kang SY, Ha SY, Kim ST, Park SH, Kang WK, Choi MG, et al. 2014 High-throughput sequencing and copy number variation detection using formalin fixed embedded tissue in metastatic gastric cancer. PLOS ONE 9 e111693. (doi:10.1371/journal.pone.0111693)

Landa I, Ganly I, Chan TA, Mitsutake N, Matsuse M, Ibrahimpasic T, Ghossein RA \& Fagin JA 2013 Frequent somatic TERT promoter mutations in thyroid cancer: higher prevalence in advanced forms of the disease. Journal of Clinical Endocrinology and Metabolism 98 E1562-E1566. (doi:10.1210/jc.2013-2383)

Lee ST, Kim SW, Ki CS, Jang JH, Shin JH, Oh YL, Kim JW \& Chung JH 2012 Clinical implication of highly sensitive detection of the BRAF V600E mutation in fine-needle aspirations of thyroid nodules: a comparative analysis of three molecular assays in 4585

Published by Bioscientifica Ltc 
consecutive cases in a BRAF V600E mutation-prevalent area. Journal of Clinical Endocrinology and Metabolism 97 2299-2306. (doi:10.1210/jc.2011-3135)

Liu X, Bishop J, Shan Y, Pai S, Liu D, Murugan AK, Sun H, El-Naggar AK \& Xing M 2013 Highly prevalent TERT promoter mutations in aggressive thyroid cancers. Endocrine-Related Cancer 20 603-610. (doi:10.1530/erc-13-0210)

Liu T, Wang N, Cao J, Sofiadis A, Dinets A, Zedenius J, Larsson C \& Xu D 2014a The age- and shorter telomere-dependent TERT promoter mutation in follicular thyroid cell-derived carcinomas. Oncogene 33 4978-4984. (doi:10.1038/onc.2013.446)

Liu X, Qu S, Liu R, Sheng C, Shi X, Zhu G, Murugan AK, Guan H, Yu H, Wang Y, et al. 2014b TERT promoter mutations and their association with BRAF V600E mutation and aggressive clinicopathological characteristics of thyroid cancer. Journal of Clinical Endocrinology and Metabolism 99 E1130-E1136. (doi:10.1210/jc.2013-4048)

Mazzaferri EL \& Kloos RT 2001 Clinical review 128: current approaches to primary therapy for papillary and follicular thyroid cancer. Journal of Clinical Endocrinology and Metabolism 86 1447-1463. (doi:10.1210/ jcem.86.4.7407)

Melo M, da Rocha AG, Vinagre J, Batista R, Peixoto J, Tavares C, Celestino R, Almeida A, Salgado C, Eloy C, et al. 2014 TERT promoter mutations are a major indicator of poor outcome in differentiated thyroid carcinomas. Journal of Clinical Endocrinology and Metabolism 99 E754-E765. (doi:10.1210/jc.2013-3734)

Muzza M, Colombo C, Rossi S, Tosi D, Cirello V, Perrino M, De Leo S, Magnani E, Pignatti E, Vigo B, et al. 2015 Telomerase in differentiated thyroid cancer: promoter mutations, expression and localization. Molecular and Cellular Endocrinology 399 288-295. (doi:10.1016/j.mce.2014.10.019)

Ngeow J \& Eng C 2014 TERT and BRAF in thyroid cancer: teaming up for trouble. Journal of Clinical Oncology 32 2683-2684. (doi:10.1200/ jco.2014.56.5614)

Nikiforov YE 2002 RET/PTC rearrangement in thyroid tumors. Endocrine Pathology 13 3-16. (doi:10.1385/EP:13:1:03)

Russell JP, Powell DJ, Cunnane M, Greco A, Portella G, Santoro M, Fusco A \& Rothstein JL 2000 The TRK-T1 fusion protein induces neoplastic transformation of thyroid epithelium. Oncogene 19 5729-5735. (doi:10.1038/sj.onc.1203922)

Sharma HW, Sokoloski JA, Perez JR, Maltese JY, Sartorelli AC, Stein CA, Nichols G, Khaled Z, Telang NT \& Narayanan R 1995 Differentiation of immortal cells inhibits telomerase activity. PNAS 92 12343-12346. (doi:10.1073/pnas.92.26.12343)

Shi X, Liu R, Qu S, Zhu G, Bishop J, Liu X, Sun H, Shan Z, Wang E, Luo Y, et al. 2015 Association of TERT promoter mutation $1,295,228$ C $>$ T with BRAF V600E mutation, older patient age, and distant metastasis in anaplastic thyroid cancer. Journal of Clinical Endocrinology and Metabolism 100 E632-E637. (doi:10.1210/jc.20143606)

Sohn SY, Park WY, Shin HT, Bae JS, Ki CS, Oh YL, Kim SW \& Chung JH 2016 Highly concordant key genetic alterations in primary tumors and matched distant metastases in differentiated thyroid cancer. Thyroid 26 672-682. (doi:10.1089/thy.2015.0527)

Song YS, Lim JA \& Park YJ 2015 Mutation profile of well-differentiated thyroid cancer in Asians. Endocrinology and Metabolism 30 252-262. (doi:10.3803/EnM.2015.30.3.252)

Song YS, Lim JA, Choi H, Won JK, Moon JH, Cho SW, Lee KE, Park YJ, Yi KH, Park do J, et al. 2016 Prognostic effects of TERT promoter mutations are enhanced by coexistence with BRAF or RAS mutations and strengthen the risk prediction by the ATA or TNM staging system in differentiated thyroid cancer patients. Cancer $\mathbf{1 2 2}$ 1370-1379. (doi:10.1002/cncr.29934)

Strahl T, Gille H \& Shaw PE 1996 Selective response of ternary complex factor Sap1a to different mitogen-activated protein kinase subgroups. PNAS 93 11563-11568. (doi:10.1073/pnas.93.21.11563)

The Cancer Genome Atlas Research Network 2014 Integrated genomic characterization of papillary thyroid carcinoma. Cell $\mathbf{1 5 9}$ 676-690. (doi:10.1016/j.cell.2014.09.050)

Vaccarella S, Dal Maso L, Laversanne M, Bray F, Plummer M \& Franceschi S 2015 The impact of diagnostic changes on the rise in thyroid cancer incidence: a population-based study in selected highresource countries. Thyroid 25 1127-1136. (doi:10.1089/thy.2015.0116)

Vinagre J, Almeida A, Populo H, Batista R, Lyra J, Pinto V, Coelho R, Celestino R, Prazeres H, Lima L, et al. 2013 Frequency of TERT promoter mutations in human cancers. Nature Communications 4 2185. (doi:10.1038/ncomms3185)

Vinagre J, Pinto V, Celestino R, Reis M, Populo H, Boaventura P, Melo M, Catarino T, Lima J, Lopes JM, et al. 2014 Telomerase promoter mutations in cancer: an emerging molecular biomarker? Virchows Archiv 465 119-133. (doi:10.1007/s00428-014-1608-4)

Xing M 2016 Clinical utility of RAS mutations in thyroid cancer: a blurred picture now emerging clearer. BMC Medicine 1412. (doi:10.1186/s12916-016-0559-9)

Xing M, Alzahrani AS, Carson KA, Viola D, Elisei R, Bendlova B, Yip L, Mian C, Vianello F, Tuttle RM, et al. 2013a Association between BRAF V600E mutation and mortality in patients with papillary thyroid cancer. JAMA 309 1493-1501. (doi:10.1001/jama.2013.3190)

Xing M, Haugen BR \& Schlumberger M $2013 b$ Progress in molecularbased management of differentiated thyroid cancer. Lancet $\mathbf{3 8 1}$ 1058-1069. (doi:10.1016/s0140-6736(13)60109-9)

Xing M, Liu R \& Bishop J 2014a TERT promoter and BRAF mutations cooperatively promote papillary thyroid cancer-related mortality. Thyroid 24 A-131. (doi:10.1089/thy.2014.2410.abstracts.sc)

Xing M, Liu R, Liu X, Murugan AK, Zhu G, Zeiger MA, Pai S \& Bishop J $2014 b$ BRAF V600E and TERT promoter mutations cooperatively identify the most aggressive papillary thyroid cancer with highest recurrence. Journal of Clinical Oncology 32 2718-2726. (doi:10.1200/ jco.2014.55.5094)

Xing M, Alzahrani AS, Carson KA, Shong YK, Kim TY, Viola D, Elisei R, Bendlova B, Yip L, Mian C, et al. 2015 Association between BRAF V600E mutation and recurrence of papillary thyroid cancer. Journal of Clinical Oncology 33 42-50. (doi:10.1200/jco.2014.56.8253)

Received in final form 10 August 2016

Accepted 15 August 2016

Accepted Preprint published online 15 August 2016
() 2016 Society for Endocrinology Printed in Great Britain
Published by Bioscientifica Ltd. 